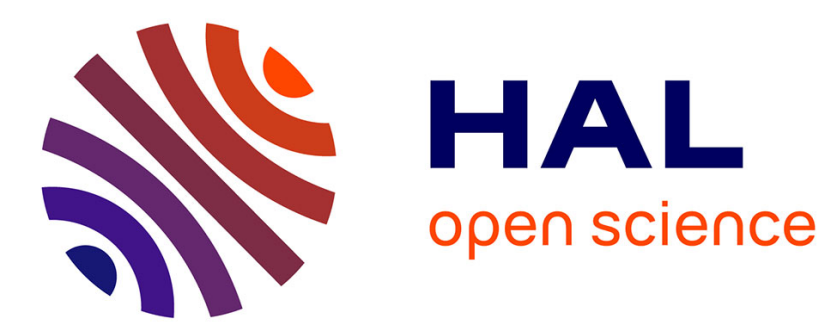

\title{
The electro-optic r22 coefficients and acoustic contributions in LiTaO3 crystal
}

Haitham Saadon, Nicéphore Théofanous, Michel Aillerie, Mustapha Abarkan, Jean-Paul Salvestrini, Marc Fontana

\section{- To cite this version:}

Haitham Saadon, Nicéphore Théofanous, Michel Aillerie, Mustapha Abarkan, Jean-Paul Salvestrini, et al.. The electro-optic r22 coefficients and acoustic contributions in LiTaO3 crystal. Journal of Optics A: Pure and Applied Optics, 2006, 8, pp.677-682 . 10.1088/1464-4258/8/8/009 . hal-00186002

\section{HAL Id: hal-00186002 https://hal.science/hal-00186002}

Submitted on 2 Dec 2021

HAL is a multi-disciplinary open access archive for the deposit and dissemination of scientific research documents, whether they are published or not. The documents may come from teaching and research institutions in France or abroad, or from public or private research centers.
L'archive ouverte pluridisciplinaire HAL, est destinée au dépôt et à la diffusion de documents scientifiques de niveau recherche, publiés ou non, émanant des établissements d'enseignement et de recherche français ou étrangers, des laboratoires publics ou privés.

\section{(ㄷ)(1) $\$$}

Distributed under a Creative Commons Attribution - NonCommerciall 4.0 International 


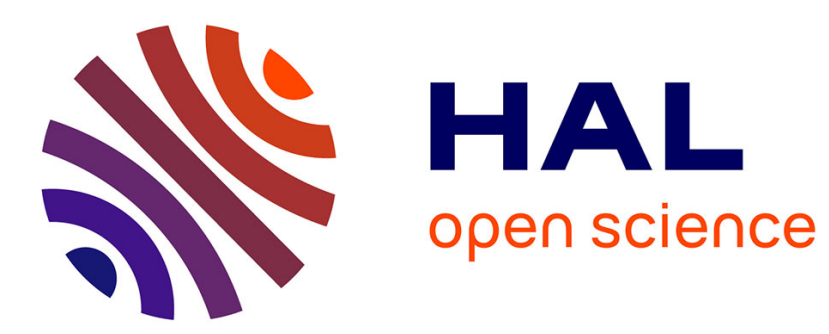

\section{The electro-optic r22 coefficients and acoustic contributions in LiTaO3 crystal}

Haitham Saadon, Nicéphore Théofanous, Michel Aillerie, Mustapha Abarkan, Jean-Paul Salvestrini, Marc Fontana

\section{- To cite this version:}

Haitham Saadon, Nicéphore Théofanous, Michel Aillerie, Mustapha Abarkan, Jean-Paul Salvestrini, et al.. The electro-optic r22 coefficients and acoustic contributions in LiTaO3 crystal. Journal of Optics A: Pure and Applied Optics, IOP Publishing, 2006, 8, pp.677-682. 10.1088/1464-4258/8/8/009 . hal-00186002

\section{HAL Id: hal-00186002 \\ https://hal.archives-ouvertes.fr/hal-00186002}

Submitted on 2 Dec 2021

HAL is a multi-disciplinary open access archive for the deposit and dissemination of scientific research documents, whether they are published or not. The documents may come from teaching and research institutions in France or abroad, or from public or private research centers.
L'archive ouverte pluridisciplinaire HAL, est destinée au dépôt et à la diffusion de documents scientifiques de niveau recherche, publiés ou non, émanant des établissements d'enseignement et de recherche français ou étrangers, des laboratoires publics ou privés. 


\title{
The electro-optic $r_{22}$ coefficients and acoustic contributions in $\mathrm{LiTaO}_{3}$ crystal
}

\author{
H L Saadon ${ }^{1}$, N Théofanous ${ }^{1}$, M Aillerie ${ }^{2}$, M Abarkan ${ }^{2}$, \\ J P Salvestrini ${ }^{2}$ and M D Fontana ${ }^{2}$ \\ ${ }^{1}$ Department of Informatics and Telecommunications, Optoelectronics Group, \\ University of Athens, Panepistimiopolis, Ilisia, GR-157 84 Athens, Greece \\ 2 Laboratoire Matériaux Optiques, Photonique et Systèmes, UMR CNRS 7132, \\ Université de Metz et Supélec, 2, rue E. Belin, 57070 Metz, France \\ E-mail: optel@di.uoa.gr (N Théofanous) and aillerie@metz.supelec.fr
}

\begin{abstract}
The electro-optic (EO) coefficients $r_{22}$ of a congruent $\mathrm{LiTaO}_{3}$ bulk crystal, with dimensions of $6 \times 5 \times 20 \mathrm{~mm}^{3}$, have been measured over a wide frequency range (from dc up to $150 \mathrm{MHz}$ ) using the novel and elaborate step-voltage time-response method (TRM). At low frequencies, these results are compared with those obtained with the frequency-doubling EO-modulation (FDEOM) method. From these measurements, the clamped and unclamped EO coefficients, $r^{\mathrm{S}}$, respectively, have been derived

and the acoustic contribution $r_{22}^{\mathrm{a}}$ to the EO effect has been deduced and compared with theoretically calculated values. Also, using the values of acoustic contribution, $r^{\mathrm{a}}$, the true value of the EO coefficient $r_{22}$ has been extracted. Lastly, the above results are compared with those obtained for a pure congruent $\mathrm{LiNbO}_{3}$ crystal in the framework of a typical intensity-modulation (IM) EO system.
\end{abstract}

Keywords: Pockels effect, time and frequency response, piezo-electric effect, acoustic resonances

\section{Introduction}

As is well known [1], the $\mathrm{LiTaO}_{3}$ (or LT) crystal belongs to the same $\mathrm{ABO}_{3}$-type oxygen-octahedra ferroelectric family as the $\mathrm{LiNbO}_{3}$ (or LN) crystal, which is widely used in electrooptical (EO) and relevant photonic applications [2]. In such cases, and more particularly in intensity-modulation (IM) EO systems, the LT crystal could be an efficient substitute for LN as a modulator crystal, because of its similar structure and its relatively higher or even comparable figures of merit, such as the $n^{3} r$ product, the half-wave voltage, and the electro-optic coefficients [3]. Unfortunately, until recently, LT presented non-negligible problems (e.g. cracking effects) in its crystal growth, and an increased sensitivity to humidity, as well a relatively higher thermo-optic dependence of the natural birefringence $n_{\mathrm{o}}-n_{\mathrm{e}}$.

Nevertheless, in recent years, water-resistant LT crystals, of very good optical quality and free of cracking effects, have begun to be produced and new interest has started to develop in this crystal [3-8]. Moreover, as has been proved in a recent paper [9], in an IM electro-optic modulation system the principal quantity of interest, which is the EO modulation depth, $m$, is much more temperature dependent in the case of LN than in the case of its LT counterpart. Obviously, this result could advocate the use of LT instead of LN in the above EOmodulation systems.

Incited by the above, we have made use of modern methods to study experimentally the electro-optic and relevant effects in rectangular $\mathrm{LiTaO}_{3}$ crystal slabs of various lengths on the basis of a Sénarmont-type arrangement. Part of this study has quite recently been published elsewhere [10]. The present paper exhibits the results of EO determinations in LT regarding the EO coefficients $r_{22}^{\mathrm{T}}$ and $r_{22}^{\mathrm{S}}$, with emphasis placed on the acoustic contribution to the EO effect and the true value of the $r_{22}$ coefficient for a long crystal sample. The above measurements have been performed using, for increased versatility and accuracy, elaborate techniques such as the frequency-doubling EO-modulation (FDEOM) method and 
the step-voltage time-response (TRM) method $[11,12]$. The first method is more appropriate for dc or low EO-modulation frequencies, while the latter yields values of EO coefficient over a wide frequency range and allows us to obtain and analyse the corresponding frequency dispersion of the EO effect. Using both of these methods, we have determined the acoustic contribution, $r_{22}^{\mathrm{a}}$, to the EO effect and the true value of $r_{22}$ corresponding to the 'direct' EO effect, which represents the straightforward influence of the electric field on the refractive index. Finally, the results extracted in this work are compared to each other and to those obtained for a congruent $\mathrm{LiNbO}_{3}$ (or LN) crystal.

\section{Equations of electro-optics for LT and LN crystals}

At room temperature, both LT and LN crystals belong to the trigonal system and have the structure of the crystal class (point group) $3 m$. As can be seen from the EO tensor of this class, the electro-optic behaviour of these crystals can be described by means of the four independent linear EO coefficients $r_{13}, r_{33}$, $r_{22}$ and $r_{51}[13]$.

In the presence of an external electric field $\vec{E}$ applied to an EO crystal such as LT or LN, the total birefringence of the crystal can be expressed by the linear approximation [14]

$$
\Delta n=\Delta n^{(0)}+\Delta n(E)
$$

where $\Delta n^{(0)}$ is the natural or spontaneous birefringence and $\Delta n(E)$ is the field-induced or electro-optic birefringence. The corresponding total differential phase shift or relative retardation is given by $[13,14]$

$$
\Gamma=\Gamma^{(0)}+\Gamma(E),
$$

where

$$
\Gamma^{(0)}=(2 \pi L / \lambda) \Delta n^{(0)}, \quad \Gamma(E)=(2 \pi L / \lambda) \Delta n(E)
$$

are, respectively, the spontaneous (or natural) and the fieldinduced differential phase retardations throughout the crystal sample. In these equations, $L$ is the length of the crystal along the propagating light beam and $\lambda$ is the wavelength of the light in a vacuum.

An important configuration, bringing into direct action the EO coefficient $r_{22}$ alone, is the transverse configuration in which the electric field $\vec{E}$ is applied along the $Y$ crystal axis and the light beam propagates along the $Z$ axis (which is the natural optical axis of the crystal). By means of calculations on the EO tensor and the optical indicatrix, it is proven that, for this configuration (which we shall call the $r_{22}$ configuration), the field-induced birefringence has its fast and slow axes in the $(X, Y)$ plane and its value is expressed by [15]

$$
\Delta n(E)=\Delta n_{x y}(E)=n_{0}^{3} r_{22} E,
$$

where $n_{0}$ is the ordinary refractive index of the crystal without a field. Combining equations (3) and (4), it is easily deduced that, in the above configuration, the EO coefficient $r_{22}$ is ruled by the relationship

$$
r_{22}=(\lambda / 2 \pi)\left[\Gamma(E) / L n_{0}^{3} E\right] .
$$

\section{EO frequency dispersion and acoustic contributions}

It is known that, in general, the EO parameters of inorganic crystals present an EO frequency dispersion, i.e. they depend on the frequency $f$ of the ac electric field applied for EO modulation. This dispersion is mainly due to various contributions, of non-electro-optic origin, to the electro-optic effect, which are unequal in different frequency ranges [15]. As a result of this EO frequency dispersion, the value $\left(r^{\mathrm{T}}\right)$ of an EO coefficient under unclamped (constant stress) conditions differs from its value $\left(r^{\mathrm{S}}\right)$ under clamped (constant strain) conditions, in accordance with the relationship [13-16]

$$
r^{\mathrm{T}}=r^{\mathrm{S}}+r^{\mathrm{a}}
$$

where $r^{\mathrm{a}}$ denotes the acoustic contribution to the EO effect. This contribution reflects the piezo-optic effect due to the crystal deformation caused by the inverse piezo-electric effect. It is also of note that $r^{\mathrm{T}}$ expresses the low-frequency EO response and $r^{\mathrm{S}}$ the high-frequency $\mathrm{EO}$ response, which is composed of the ionic $\left(r^{\mathrm{i}}\right)$ and electronic $\left(r^{\mathrm{e}}\right)$ contributions, i.e. $r^{\mathrm{S}}=r^{\mathrm{i}}+r^{\mathrm{e}}$.

According to the above, for a given configuration, the effective acoustic contribution $r^{\mathrm{a}}$ can be determined as being equal to the difference between the two levels appearing in the EO dispersion curve, $r(f)$, far before and beyond the intermediate piezo-resonances. On the other hand, on the basis of equation (6), one can formalize an acoustic tensor, $\mathbf{r}^{\mathrm{a}}$, corresponding to the EO tensor of the crystal. The components $r_{i j, k}^{\mathrm{a}}$ of this $\mathbf{r}^{\mathrm{a}}$ tensor are related to the components $p_{i j, l m}$ and $d_{l m, k}$ of the elasto-optic (p) and the piezo-electric (d) tensors, respectively, by means of the equations [15]

$$
r_{i j, k}^{\mathrm{a}}=\sum_{l m} p_{i j, l m} d_{l m, k}
$$

Taking into account the symmetry properties and specific forms of the above tensors $\mathbf{r}, \mathbf{p}$, and $\mathbf{d}$ for the point group $(3 m)$, hence for both LN and LT crystals [15] it is easily deduced from equation (7) that, in the present case, the acoustic contribution to $r_{22}$ will be given by the expression

$$
r_{22}^{\mathrm{a}}=\left(p_{11}-p_{12}\right) d_{22}-p_{14} d_{15},
$$

where $p_{11}, p_{12}, p_{14}$ and $d_{22}, d_{15}$ are elements (non-vanishing components) of the $\mathbf{p}$ and $\mathbf{d}$ tensors, respectively, in their contracted form.

\section{Experimental methods and techniques}

\subsection{System arrangement}

The electro-optical measurements under consideration were carried out on the basis of the Sénarmont-type optical setup shown in figure 1(a). In this arrangement, the crystal sample $S$ is inserted between a polarizer $\mathrm{P}$ and a quarter-wave plate $\mathrm{Q}$, both oriented with their axes at $45^{\circ}$ to the EO-birefringence axes of the crystal. Another polarizer, playing the role of an analyser, A, is placed after the quarter-wave plate, at the output end of the setup, and is oriented with its axis at an azimuthal angle $\beta$ with respect to the fast birefringence axis 


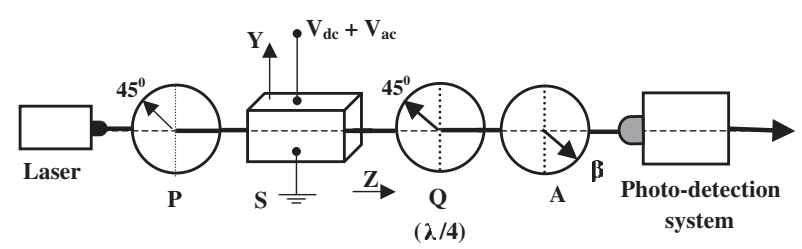

(a)

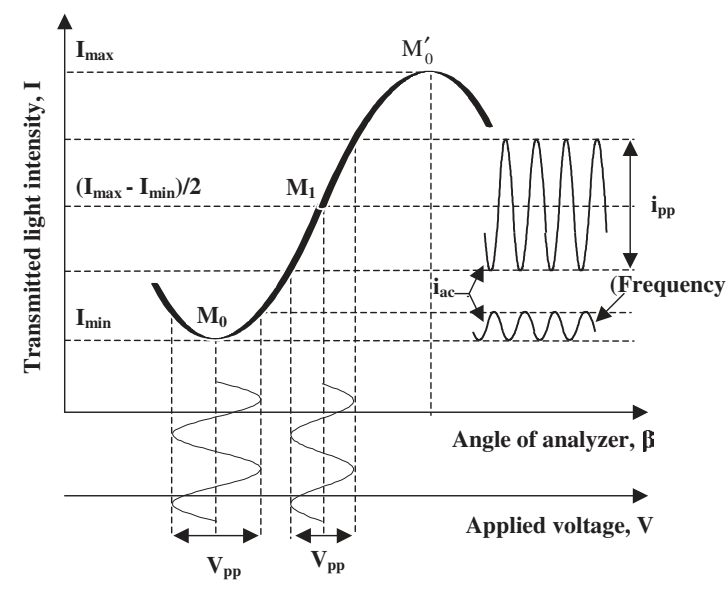

(b)

Figure 1. (a) Sénarmont-type setup used for EO measurements and (b) optical transmission of the system as a function of the analyser angle $\beta$ or the applied voltage $V$.

of the crystal. Under these conditions, the transfer function for the light intensity transmitted throughout the setup is ruled by the equation $[11,17]$

$$
T=I / I_{0}=(1 / 2)[1-\gamma \sin (\Gamma-2 \beta)]
$$

where $I_{0}$ is the light intensity incident to the crystal, $I$ is the light intensity emerging from the system (photodetected output), and $\gamma=\left(I_{\max }-I_{\min }\right) /\left(I_{\max }+I_{\min }\right)$ denotes the contrast ratio, which is supposed to be a constant parameter. The minimum and maximum values, $I_{\min }$ and $I_{\max }$, respectively, of the light intensity $I$ are as shown in figure 1(b), in which the characteristic function $I-\beta$ is plotted according to equation (9). The $I-V$ function can be derived from the $I-\beta$ function after taking into account equations (2)-(4) and $V=E d$, where $d$ is the transverse width of the crystal.

For our EO measurements we have used, as a quiescent or bias point on the $I-\beta$ or the $I-V$ characteristic of figure $1(\mathrm{~b})$, either of the following two specific working points: the first is $M_{0}$, representing the extinction (minimum-transmission) point, and the second is $M_{1}$, representing the maximum-linearity (half-transmission) point. In the case of an ac voltage of frequency $f$, added to the bias voltage $V_{\mathrm{dc}}$, the first bias point practically provides an $I$ signal of frequency $2 f$, and therefore $M_{0}$ is also called the frequency-doubling position.

\subsection{Methods of measurements}

In the present work, we have principally employed a novel, elaborate technique of EO measurement that is based on the electro-optic time response of a crystal to a step voltage pulse. This method, which is able to provide (with one single electric pulse) the values and the frequency dispersion curve of an EO coefficient, is called the 'time-response method' or TRM [12]. The results thus obtained have been used to determine the clamped and the unclamped coefficients, $r_{22}^{\mathrm{S}}$ and $r_{22}^{\mathrm{T}}$, respectively, for various frequencies.

To apply the TRM method, the maximum-linearity point $M_{1}$ of the $I-V$ transfer function is chosen as the bias working point, which corresponds to $50 \%$ transmission, with a quiescent output intensity equal to $\left(I_{\max }-I_{\min }\right) / 2$. At this working point, it is proven that, as a result of the EO effect for the $r_{22}$ configuration, a step voltage $\Delta V(t)$ induces in the instantaneous value $i(t)$ of the transmitted light intensity a variation given by $[9,12]$.

$$
\Delta i(t)=\left(I_{m} / 2 A\right) r_{22}(t) \otimes \Delta V(t)
$$

where $t$ is the time variable, $\otimes$ denotes the convolution operator, $A$ is an auxiliary constant $\left(A=\lambda d / \pi n_{0}^{3} L\right)$, and $I_{m}=I_{\max }-I_{\min }$, which represents the maximum change of $i$ over the transfer function. For any frequency $f$, the frequency-dependent $\mathrm{EO}$ coefficient $r_{22}(f)$ can be calculated from the ratio of the quantities $\Delta i(f)$ and $\Delta V(f)$ after applying the $Z$-transformation on the signals $\Delta i(t)$ and $\Delta V(t)$ of equation (10), which leads to the formula

$$
r_{22}(f)=\left(2 A / I_{m}\right)[\Delta i(f) / \Delta V(f)] .
$$

This technique, supported by appropriate computer-aided processing, allows us to obtain the frequency dispersion of the EO coefficient under consideration over a wide frequency range. In our measurements, this range was from dc up to $150 \mathrm{MHz}$ (the latter limit depending only on the rise time of the voltage pulse employed).

On the other hand, for comparison purposes, we have also measured $r_{22}$ at dc and low frequencies using one of the more precise classical methods [17], namely the 'frequencydoubling electro-optic method', or FDEOM [11]. This very accurate technique has been used to check, at low frequencies, the precision and reliability of the results obtained by means of the novel TRM method.

In the FDEOM method, by using an adjustable bias voltage $V_{\mathrm{dc}}$, the minimum-transmission point $M_{0}$ of the characteristic curve $I-V$ (figure 1(b)) is continuously established as the quiescent working point, while an ac voltage, $V_{\text {ac }}$, is applied to the EO crystal. If the photodetection system (including the monitoring oscilloscope) is sufficiently sensitive, a very clear and abrupt frequency doubling $(2 f)$ of the ac photodetected output is observed on the oscilloscope as soon as $M_{0}$ is located by appropriately adjusting $V_{\mathrm{dc}}$. The FDEOM method allows us to determine, with increased accuracy, the dc (static) or low-frequency EO coefficient $r_{22}$ in the following way [11]: with an initial voltage $V_{\mathrm{dc}}=$ $V_{0}$, creating an electro-optically induced retardation $\Gamma_{0}$, one measures the azimuthal angle, $\beta_{0}=\Gamma_{0} / 2$, of the analyser needed to achieve a clear frequency doubling of the waveform on the oscilloscope screen. Then another dc voltage $V_{\mathrm{dc}}=V$, creating a new value of retardation $\Gamma_{\mathrm{dc}}$, is applied, as a result of which the frequency doubling is distorted and a new azimuthal angle of the analyser, $\beta=\Gamma_{\mathrm{dc}} / 2$, is found to be needed for restoration of the frequency doubling. It is proven that 


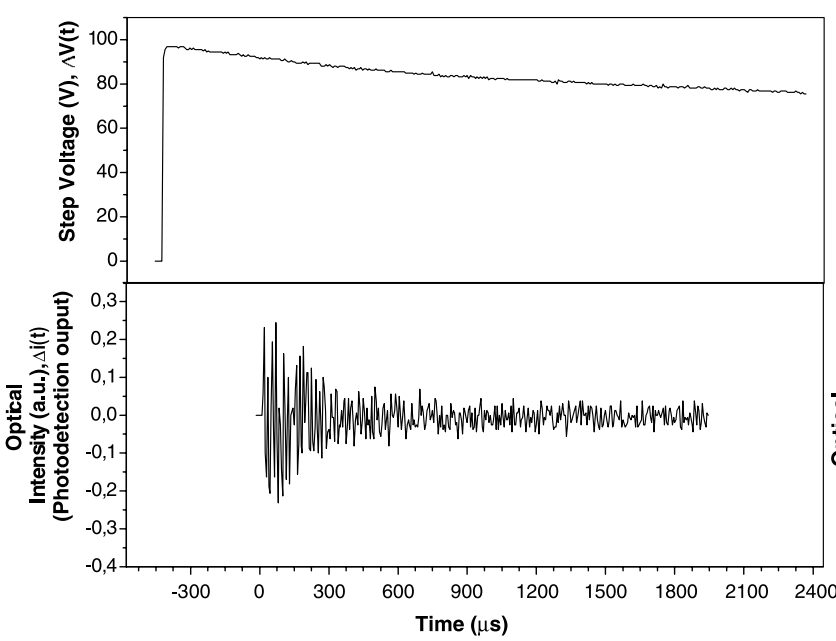

(a)

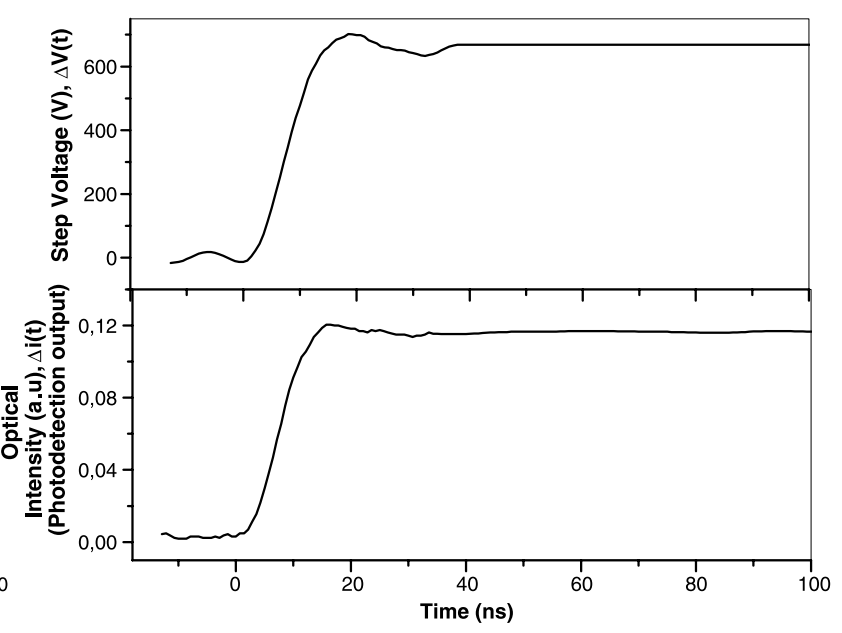

(b)

Figure 2. Time waveform of the applied step voltage and the photodetected output intensity for the LT crystal: (a) long-time response and (b) short-time response.

the dc or low-frequency EO coefficient, such as the $r_{22}$ under consideration, can be calculated by means of the equation [11]

$$
r_{22}=2 A\left(\frac{\delta \beta}{\delta V}\right)=A\left(\frac{\delta \Gamma_{\mathrm{dc}}}{\delta V}\right)
$$

where $\delta \beta=\beta-\beta_{0}=\delta \Gamma_{\mathrm{dc}} / 2$, with $\delta \Gamma_{\mathrm{dc}}=\Gamma_{\mathrm{dc}}-\Gamma_{0}$ being the electro-optically induced retardation, $\delta V_{\mathrm{dc}}=V-V_{0}$, and (for the $r_{22}$ configuration) $A=\lambda d / \pi n_{0}^{3} L$.

\section{Experimental results}

The electro-optic measurements under presentation have been performed on a single $6 \times 5 \times 20 \mathrm{~mm}^{3}$ congruent $\mathrm{LiTaO}_{3}$ (or LT) crystal using a $5 \mathrm{~mW} \mathrm{He}-\mathrm{Ne}$ laser beam at $\lambda=633 \mathrm{~nm}$. It is worth noting that these measurements were particularly devoted to the EO coefficient $r_{22}$ of LT, because this can show off even better the precision and sensitivity capabilities of the methods employed; at low frequencies, this coefficient has a very small value, which is expected to be of the order of $0.1 \mathrm{pm} \mathrm{V}^{-1}$ [15]. In addition, in the configuration used for the measurement of $r_{22}$, the laser beam propagates along the optical axis and therefore there does not exist any typical thermo-optic effect, which could falsify the EO measurements.

To implement the TRM method for the determination of the EO coefficients $r_{22}$ over the wide frequency range from dc up to $150 \mathrm{MHz}$, in the system in figure 1 (biased at the point $M_{1}$ ) we have used a fast step-function generator offering a rise time of $1 \mathrm{~ns}$. Figure 2 depicts the waveforms recorded on the oscilloscope for both the applied step voltage $\Delta V(t)$ and the corresponding photodetected optical intensity signal $\Delta i(t)$.

Figure 2(a) illustrates the long-time response, obtained with a voltage pulse of long duration, which corresponds to the low-frequency EO effect. In this case, the amplitude (jump) of the step voltage was limited to $100 \mathrm{~V}$ to avoid unacceptably high thermal dissipation in the step-voltage amplifier due to the large duration of the electric pulse. The relatively small decline in the step pulse, observed in figure 2(a), was unavoidable because of the non-zero RC constant of the highpower electrical circuit, including the switched step-voltage amplifier, the coaxial cables and the crystal under test (see the equivalent circuit in [12]).

The short-time response, which is shown in figure 2(b), corresponds to the high-frequency EO effect. In this case, to have a larger dynamic range, for the step voltage we have used a higher amplitude, of nearly $700 \mathrm{~V}$. Such a high voltage was acceptable because of the clearly lower thermal dissipation in the electric circuit due to the short duration of the voltage pulse.

As seen from figure 2(a), in the long-time response the output optical signal $\Delta i(t)$ appears to oscillate about a mean value. The periods of the principal components of these oscillations are equal to the inverse values of the frequencies of the main piezo-electric resonances in the crystal. The oscillations tend to decay after several tens of microseconds and cease to exist for a time shorter than $0.2 \mu \mathrm{s}$, which is the minimum time needed for propagation of the acoustic waves throughout the crystal. This result was obtained after appropriate signal processing of the output, including highfrequency noise filtering and suppression of the temporal shift from the unequal lengths of the electrical wires. Due to the large length of the crystal $(20 \mathrm{~mm})$, and hence to the long interaction between the light beam and the electric field throughout the sample, the relatively low step voltage that we have used was sufficient to achieve a satisfactory signal-to-noise ratio, $(\mathrm{S} / \mathrm{N})$. It is also worth noting that the amplitude (height) of the photodetected output pulse appears very different between short-time and long-time responses, which indicates that a large acoustic contribution to the $r_{22}$ value should be expected.

Applying equation (11) to the data and the results plotted in figures 2(a) and (b) together with the mathematical treatment described previously in relation to equation (10), we have determined the values of $r_{22}$ for various frequencies. Using these values, we have obtained the frequency dispersion curve depicted in figure 3. This figure shows that, as is expected normally, the unclamped EO coefficient $r_{22}^{\mathrm{T}}$ remains practically constant over the whole frequency band below the main resonances and there has a value equal to $0.1 \mathrm{pm} \mathrm{V}^{-1}$, which has been found to be in good agreement with the value obtained 
The electro-optic $r_{22}$ coefficients and acoustic contributions in $\mathrm{LiTaO}_{3}$ crystal

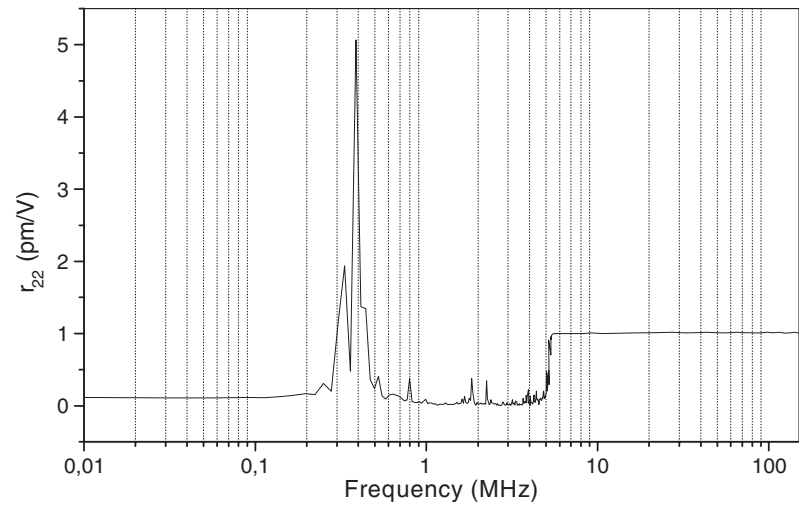

Figure 3. Curve of the frequency dependence ( $f$-dispersion) obtained for the EO coefficient $r_{22}$ in our LT sample.

by means of the FDEOM method. On the other hand, at high frequencies, beyond $5 \mathrm{MHz}$ and up to $150 \mathrm{MHz}$, the clamped EO coefficient $r_{22}^{\mathrm{S}}$ is also found to be constant, with a value equal to $1 \mathrm{pm} \mathrm{V}^{-1}$. This value is quite consistent with the value found with other techniques applied to other crystal samples [18].

Finally, we have determined $r_{22}$ at dc or low frequencies using the FDEOM method, with the configuration depicted in figure 1. In this experiment, an ac (modulating) voltage of $150 \mathrm{~V} \mathrm{p}-\mathrm{p}$ at $1 \mathrm{kHz}$ has been employed in series with a dc voltage $V=V_{\mathrm{dc}}$ adjustable from -300 to $+300 \mathrm{~V}$, and vice versa. As seen in figure 4 , the $\Gamma_{\mathrm{dc}}-V$ curve thus obtained exhibits a markedly linear dependence of $\Gamma_{\mathrm{dc}}$ on the applied dc voltage $V$, which proves the absence of higherorder electro-optic effects in LT. As can be seen from [5], this dependence is clearly more linear than that holding for $r_{c}$ in LN. To increase the accuracy in the determination of the (unclamped) EO coefficient $r_{22}$, we have used the slope $\delta \Gamma_{\mathrm{dc}} / \delta V$ of the entire curve (straight line) $\Gamma_{\mathrm{dc}}-V$ of figure 4 into equation (12). So, for $r_{22}$ we have obtained a static (dc) value equal to $r_{22}^{\mathrm{T}}=0.1 \mathrm{pm} \mathrm{V}^{-1}$. This value is identical to the result previously extracted by means of the TRM method and is satisfactorily consistent with the values recorded in the literature [15]. On the basis of equation (12), the relative error in the determination of this coefficient can be calculated using the formula

$$
\frac{\delta r_{22}}{r_{22}}=\frac{\delta L}{L}+\frac{\delta d}{d}+3 \frac{\delta n_{0}}{n_{0}}+\frac{\delta \Gamma}{\Gamma}+\frac{\delta V}{V} .
$$

Substituting into this relationship the values of the various relative errors estimated for our experimentation, we have found $\delta r_{22} / r_{22} \approx 2.6 \%$.

\section{Acoustic contribution and true EO effect in LT}

The acoustic contribution $r_{22}^{\mathrm{a}}$ to the EO effect for the $r_{22}$ configuration used in this work can now be determined if we make use of equation (6), which yields $r_{22}^{\mathrm{a}}=r_{22}^{\mathrm{T}}-r_{22}^{\mathrm{S}}$ From this formula, as we have found that $r_{22}^{\mathrm{T}}=0.1 \mathrm{pm} \mathrm{V}^{-1}$ and $r_{22}^{\mathrm{S}}=1 \mathrm{pm} \mathrm{V}^{-1}$, it is directly deduced that $r_{22}^{\mathrm{a}}=$ $-0.9 \mathrm{pm} \mathrm{V}^{-1}$. The negative sign of this contribution reflects the fact that, in LT, the EO coefficient $r_{22}$ is larger at high frequencies (beyond $5 \mathrm{MHz}$ ). By contrast, this sign is positive

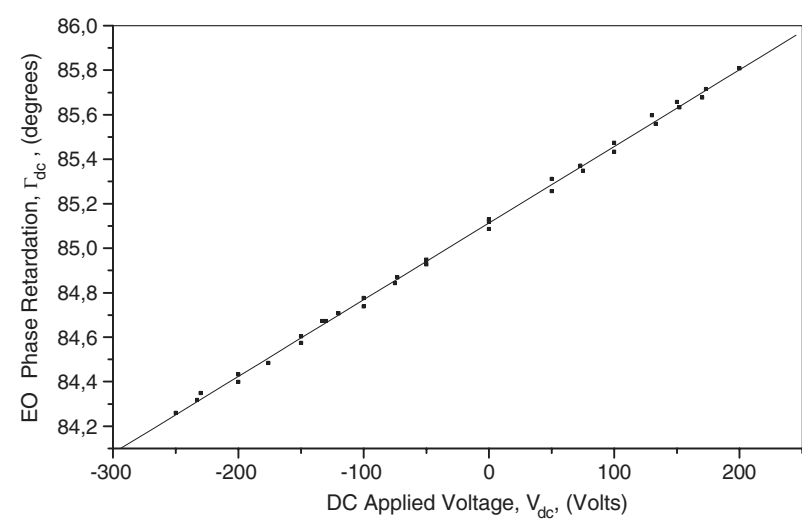

Figure 4. Dependence of the electro-optically induced phase retardation, $\Gamma_{\mathrm{dc}}$, on the applied dc voltage, $V_{\mathrm{dc}}$, as measured for our LT crystal sample.

in $\mathrm{LN}$, in which the high-frequency EO coefficient $r_{22}$ is smaller than its low-frequency value [12].

To attempt a theoretical verification of the above result, we have calculated this contribution from the product $\mathbf{p} \times \mathbf{d}$ of the elasto-optic and piezo-electric tensors, as can be derived from equation (8). Substituting into this equation the values of the required components of the above tensors holding for $\mathrm{LT}$, as available from the literature [19-21], for $r_{22}^{\mathrm{a}}$ we have found a theoretical value equal to $-0.8 \mathrm{pm} \mathrm{V}^{-1}$, and hence nearly $11 \%$ different from the measured value.

In table 1, the measured value of the acoustic contribution $r_{22}^{\mathrm{a}}$ for LT is listed in juxtaposition with its theoretical value, calculated as above, and the corresponding values measured and calculated for a pure congruent LN crystal [10], which has been taken as a basis of comparison. In addition, to compare relative values, in table 1 we have also recorded the acoustic contribution $r_{22}^{\mathrm{a}}$ as a percentage (ratio $r_{22}^{\mathrm{a}} / r_{22}^{\mathrm{T}}$ ) of the dc or low-frequency coefficient $r_{22}^{\mathrm{T}}$. From this table it is deduced that, to within experimental errors, the theory of the piezo-optic origin of the acoustic contribution, as presented in section 3 , is rather satisfactory for LT and even better for LN. It is also worth noting that, as is seen, in LT the acoustic contribution $r_{22}^{\mathrm{a}}$ is several times larger than the measured low-frequency EO coefficient $r_{22}$ itself. Accordingly, at low frequencies, in LT this contribution considerably dominates and highly restrains the apparent value of the $r_{22}$ coefficient, which is not the case for an LN crystal.

It is also interesting to deduce the 'direct' EO effect expressing the straightforward influence of the electric field on the refractive index. This can be made by subtracting from the observed total effect the secondary, or 'indirect', effect due to the crystal deformation [22]. The value of the EO coefficient corresponding to the direct effect is the true value of $r$. Based on the above, one can find the true value $r_{22}^{\prime \prime}$ of the unclamped EO coefficient $r_{22}^{\mathrm{T}}$ by means of the relationship [16]

$$
r_{22}^{\prime \prime}=r_{22}^{\mathrm{T}}-r^{\prime}
$$

where $r^{\prime}$ designates the 'indirect' EO effect. On the reasonable assumption that this effect is due only to the acoustic contribution resulting from crystal deformation, we shall have $r^{\prime}=r_{22}^{\mathrm{a}}$ (as is derived from $\mathbf{p}$ and $\mathbf{d}$ tensors). Then, the above formula with the data of table 1 yields, for $r_{22}^{\mathrm{T}}$, a true 
Table 1. Comparison between the EO coefficients and the acousto-optic difference $r_{22}^{\mathrm{T}}-r_{22}^{\mathrm{S}}$, as derived from our results, and the elements of the product $\mathbf{p} \times \mathbf{d}$ in a $\mathrm{LiTaO}_{3}$ crystal in juxtaposition with a $\mathrm{LiNbO}_{3}$ crystal.

\begin{tabular}{|c|c|c|c|c|c|}
\hline \multirow[b]{2}{*}{ Crystal } & \multirow{2}{*}{$\begin{array}{l}\text { Unclamped } \\
\text { EO coefficient } \\
r_{22}^{\mathrm{T}}\left(\mathrm{pm} \mathrm{V}^{-1}\right)\end{array}$} & \multirow{2}{*}{$\begin{array}{l}\text { Clamped } \\
\text { EO coefficient } \\
r_{22}^{\mathrm{S}}\left(\mathrm{pm} \mathrm{V}^{-1}\right)\end{array}$} & \multicolumn{2}{|c|}{ Acoustic contribution $r_{22}^{\mathrm{a}}$} & \multirow[b]{2}{*}{$\begin{array}{l}\text { Relative } \\
r^{\mathrm{a}} / r^{\mathrm{T}}(\%)\end{array}$} \\
\hline & & & $\begin{array}{l}\text { Measured } \\
\left(r^{\mathrm{T}}-r^{\mathrm{S}}\right)\left(\mathrm{pm} \mathrm{V}^{-1}\right)\end{array}$ & $\begin{array}{l}\text { Theoretical } \\
(p \times d)\end{array}$ & \\
\hline $\begin{array}{l}\mathrm{LiTaO}_{3} \\
(\mathrm{LT})\end{array}$ & $\begin{array}{l}0.1 \pm 0.02 \\
\text { (True value: } 0.9 \text { ) }\end{array}$ & 1 & -0.90 & -0.80 & -900 \\
\hline $\begin{array}{l}\mathrm{LiNbO}_{3} \\
\text { (LN) }\end{array}$ & $\begin{array}{l}6.4 \\
\text { (True value: } 3.8 \text { ) }\end{array}$ & 3.8 & 2.6 & 2.6 & 40 \\
\hline
\end{tabular}

value $r_{22}^{\prime \prime}$ equal to $0.9 \mathrm{pm} \mathrm{V}^{-1}$ for $\mathrm{LT}$ and $3.8 \mathrm{pm} \mathrm{V}^{-1}$ for $\mathrm{LN}$. Accordingly, these two true values are of a nearly similar order of magnitude, which is not the case for the corresponding total (apparent) values.

\section{Conclusions}

In the main part of this work, which is focused on the isolation of the contribution due to the acoustic-optic effect, we have measured the clamped and unclamped values of the EO coefficient $r_{22}$, and determined the corresponding acoustic contribution $r_{22}^{\mathrm{a}}$, in a long congruent $\mathrm{LiTaO}_{3}$ (or LT) crystal. These measurements have been made using accurate and/or elaborate methods, namely the step-voltage TRM and the FDEOM methods.

By applying the TRM method, the EO frequency dispersion curve $r_{22}=r(f)$ has been derived for the LT crystal under consideration. This dispersion curve has been found, in general, to be similar to that recently reported in [10]. However, possibly due to the large length of our crystal, in the present curve there exists a slight displacement of piezoresonaces to lower frequencies, together with a shift of the high-frequency plateau to the higher frequencies.

From the above dispersion curve, the low-frequency (unclamped) and high-frequency (clamped) values $r_{22}^{\mathrm{T}}$ and $r_{22}^{\mathrm{S}}$, respectively, of the LT crystal have been extracted with satisfactory accuracy. Also, the unclamped coefficient $r_{22}^{\mathrm{T}}$ has been determined using the highly accurate FDEOM method, and very good linearity has been ascertained for the EO effect in the $r_{22}$ configuration. These results proved to be quite consistent to each other and to those already reported in the literature.

Using the values of $r_{22}^{\mathrm{T}}$ and $r_{22}^{\mathrm{S}}$ thus extracted in the formula $r_{22}^{\mathrm{a}}=r_{22}^{\mathrm{T}}-r_{22}^{\mathrm{S}}$, it has been deduced that, in LT, the acoustic contribution $r_{22}^{\mathrm{a}}$ is negative and significantly stronger (nine times higher) than $r_{22}^{\mathrm{T}}$. As a result of that, in LT the acoustic contribution largely suppresses the underlying EO effect, for which we have calculated a true $r_{22}^{\mathrm{T}}$ value equal to $0.9 \mathrm{pm} \mathrm{V}^{-1}$, while the corresponding apparent (observed) value is only $0.1 \mathrm{pm} \mathrm{V}^{-1}$. This is not the case for $\mathrm{LN}$, in which the acoustic contribution is positive and less (40\% lower) than the apparent $r_{22}^{\mathrm{T}}$ value, which is equal to $6.4 \mathrm{pm} \mathrm{V}^{-1}$, with a true value of $3.8 \mathrm{pm} \mathrm{V}^{-1}$ (note that the comparison between LT and LN and all values reported for LN refer to crystals with congruent composition).

Finally, the acoustic contribution measured as above has been compared with its value calculated from the product $\mathbf{p} \times \mathbf{d}$ of the elasto-optic and piezo-electric tensors. In LT, a nonnegligible discrepancy of $11 \%$ has been observed between measured and calculated values, whereas in LN complete coincidence has been found between them. This fact could be attributed possibly to the coexistence in LT of additional side effects, besides those caused by the crystal deformation only.

\section{Acknowledgments}

This work was realised partially under the framework of the Programme 'Pythagoras II' (EPEAEK II) supported by the European Community and the Greek Government. The authors wish to acknowledge these organizations for the above support.

\section{References}

[1] Miyazawa S and Iwasaki H 1971 J. Cryst. Growth 10276

[2] Casson J L, Wang L, Libatique N J C, Jain R K, Scrymgeour D A, Gopalan V, Gahagan K T, Sander R K and Robinson J M 2002 Appl. Opt. 416416

[3] Saadon H L, Théofanous N and Aillerie M 2006 J. Phys. D: Appl. Phys. 39 2509-13

[4] Kostritskii S M, Bourson P, Aillerie M, Fontana M D and Kip D 2006 Appl. Phys. B 1-8

[5] Loyo-Menoyo M, Keeble D J, Furukawa Y and Kitamura K 2004 J. Phys.: Condens. Matter 16 9047-57

[6] Imbrock J, Bäumer C, Hesse H, Kip D and Krätzig E 2004 Appl. Phys. B 78 615-22

[7] Ren T W, He J L, Zhang C, Zhu S N, Zhu Y Y and Hang Y 2004 J. Phys.: Condens. Matter 16 3289-94

[8] Zhang V L, Kuok M H, Lim H S and Ng S C 2002 J. Phys.. Condens. Matter 14 545-53

[9] Saadon H L, Théofanous N, Aillerie M and Fontana M D 2006 Appl. Phys. B 82 423-30

[10] Abarkan M, Salvestrini J P, Fontana M D and Aillerie M 2003 Appl. Phys. B 76765

[11] Theofanous N G, Aillerie M, Fontana M D and Alexakis G E 1997 Rev. Sci. Instrum. 682138

[12] Abarkan M, Salvestrini J P, Aillerie M and Fontana M D 2003 Appl. Opt. 422346

[13] Kaminow I P 1974 An Introduction to Electro-Optic Devices (New York: Academic)

[14] Eimerl D 1987 IEEE J. Quantum Electron. 232104

[15] Yariv A and Yeh P 1984 Optical Waves in Crystals (New York: Wiley)

[16] Salvestrini J P, Fontana M D, Wyncke B and Brehat F 1997 Nonlinear Opt. 17271

[17] Aillerie M, Theofanous N and Fontana M D 2000 Appl. Phys. B 70317

[18] Lenzo P V, Turner E H, Spencer E G and Ballman A A 1966 Appl. Phys. Lett. 8081

[19] Dixon R W 1967 J. Appl. Phys. 385149

[20] Coquin G A and Pinnow D A 1971 Handbook of Laser (Clereland: A Rec Rubber Co.)

[21] Warner A W, Onoe M and Coquin G A 1967 J. Acoust. Soc. Am. 421223

[22] Cady W G 1964 Piezoelectricity vol 2 (New York: Dover) 